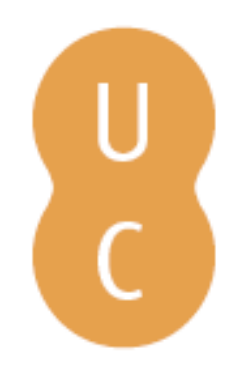

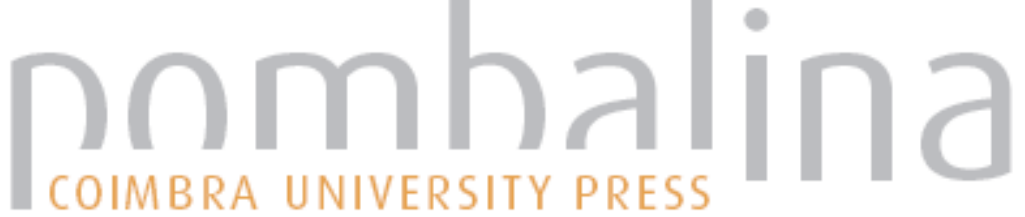

\section{Drama satírico}
Autor(es):
Vicente Sánchez, A. C.
Publicado por: Imprensa da Universidade de Coimbra
URL persistente:
URI:http://hdl.handle.net/10316.2/44020
DOI:
DOI:https://doi.org/10.14195/978-989-26-1598-1_5

Accessed : $\quad$ 26-Apr-2023 06:18:30

A navegação consulta e descarregamento dos títulos inseridos nas Bibliotecas Digitais UC Digitalis, UC Pombalina e UC Impactum, pressupõem a aceitação plena e sem reservas dos Termos e Condições de Uso destas Bibliotecas Digitais, disponíveis em https://digitalis.uc.pt/pt-pt/termos.

Conforme exposto nos referidos Termos e Condições de Uso, o descarregamento de títulos de acesso restrito requer uma licença válida de autorização devendo o utilizador aceder ao(s) documento(s) a partir de um endereço de IP da instituição detentora da supramencionada licença.

Ao utilizador é apenas permitido o descarregamento para uso pessoal, pelo que o emprego do(s) título(s) descarregado(s) para outro fim, designadamente comercial, carece de autorização do respetivo autor ou editor da obra.

Na medida em que todas as obras da UC Digitalis se encontram protegidas pelo Código do Direito de Autor e Direitos Conexos e demais legislação aplicável, toda a cópia, parcial ou total, deste documento, nos casos em que é legalmente admitida, deverá conter ou fazer-se acompanhar por este aviso.

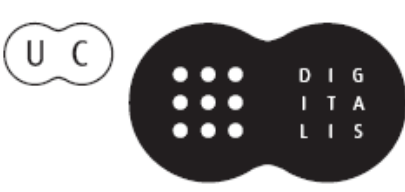




\section{Irreligiosidad y}

Literatura en la Atenas Clásica

V.M. Ramón Palerm, G. Sopeña Genzor, A.C. Vicente Sánchez (eds.)

IMPRENSA DA UNIVERSIDADE DE COIMBRA 


\subsection{Drama satírico \\ (Satyr Drama )}

A.C. Vicente SÁnchez (Orcid ID: 0000-0003-0147-370X; ana@unizar.es)

Universidad de Zaragoza

\section{5}

\section{Eurípides, EL Cíclope 316-321 (Kovacs 200I)}

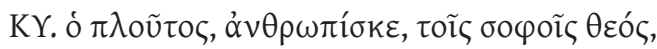

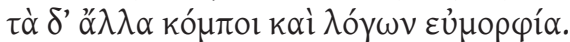

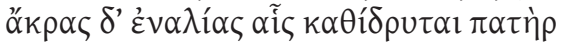

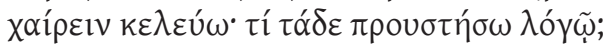

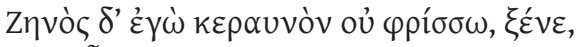

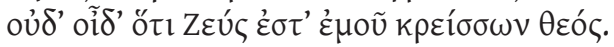

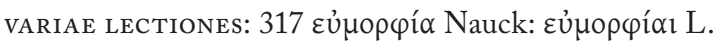

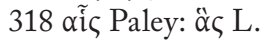

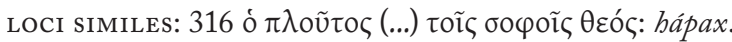

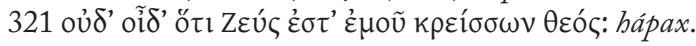

CÍ. E1 dinero, hombrecillo, es dios para los sabios, y el resto, petulancia y palabrería bonita.

Y los promontorios marinos, sobre los que se asienta mi padre, los mando a paseo. ¿Por qué los sacas a colación en tu discurso? $Y$ ante el rayo de Zeus no tiemblo yo, extranjero, ni entiendo que Zeus sea un dios más poderoso que yo.

Con estos versos comienza el Cíclope su réplica al discurso suplicatorio de Odiseo, rebatiendo los argumentos que este había esgrimido (vv. 285-312). La primera afirmación, según la cual su dios es el dinero (v. 316), se corresponde con la justificación de la Guerra de Troya que Odiseo había proporcionado

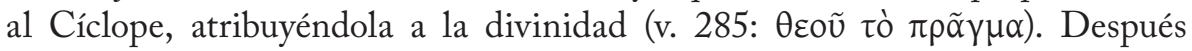
manifiesta lo poco que le importan los promontorios de su padre (vv. 318-319), que Odiseo aseguraba haber salvado (vv. 290-299). Y, a continuación, le reprocha la inutilidad de su discurso (v. 319) ya que no teme a Zeus, ni siquiera cree que sea más importante que él mismo (vv. 319-321). No solo queda patente su desprecio por los dioses y las costumbres del mundo heleno civilizado: también su lenguaje destila vulgaridad y dejade $z^{485}$. En el resto de su discurso prosigue con

${ }^{485}$ Puede apreciarse, por ejemplo, en el vocativo del v. 316 y en la expresión de los vv. 
su irreverencia hacia el mundo divino, declarando que se niega a hacer sacrificios a los dioses (v. 334), limitándolos tan solo a sí mismo y a su barriga, la más grande

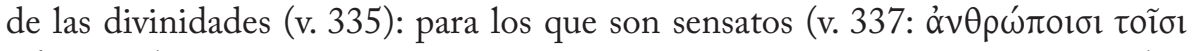
$\sigma \omega ́ \varphi \rho o \sigma ı v)$ es Zeus comer y beber todo el día, y no preocuparse por nada (vv. 336-338). Como consecuencia de sus ultrajes a la divinidad y comportamiento al margen de la civilización, sobre todo por no respetar las normas de hospitalidad helenas (vv. 299-312, 338-346), como explicaremos a continuación, Odiseo llama al Cíclope ớvóøı ${ }^{486}$ (v. 348). Prueba de la importancia de esta última cuestión

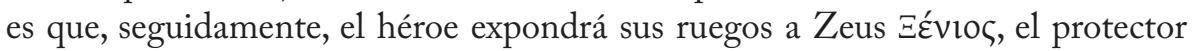
de los huéspedes ${ }^{487}$.

En este sentido, resulta interesante indagar en los términos de carácter (ir) religioso que la figura de Polifemo recibe a lo largo del drama. Ya en el prólogo,

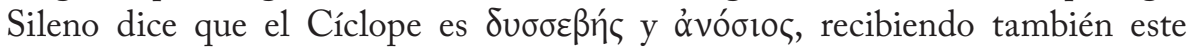
último calificativo sus comidas (vv. 26, 30, 31). El motivo por el que utiliza estos dos adjetivos de fuerte calado irreligioso no puede proceder exclusivamente de los asesinatos que comete Polifemo, pues esa es la manera en que describe a los

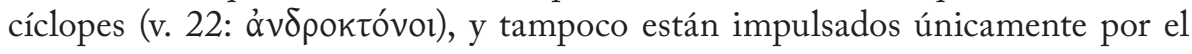
hecho de comer seres humanos: la causa primordial, que sobresale constantemente en el texto, es la falta de respeto por los dioses y por los huéspedes de acuerdo con las leyes helenas, ya que no se cumple con ninguno de los requisitos que sugieren una correcta relación de hospitalidad. Así es, cuando Sileno ve desembarcar a

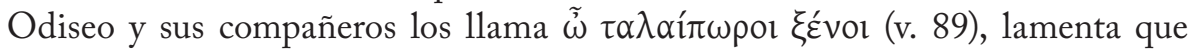

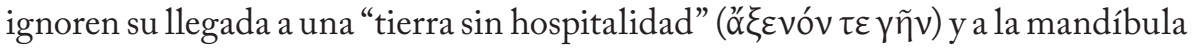
"devoradora de hombres" de Polifemo (vv. 90-93). Odiseo, entonces, pregunta a Sileno si los cíclopes que habitan esa tierra son hospitalarios y se comportan

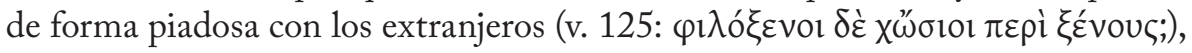
a lo que Sileno responde que para ellos las carnes de los extranjeros son las más tiernas y se comen a todo el que llega (vv. 126, 128). Por ello Odiseo suplica al Cíclope que no haga de ellos una impía comida (v. 289: ßopóv $\tau \varepsilon \delta v \sigma \sigma \varepsilon \beta \tilde{\eta})$

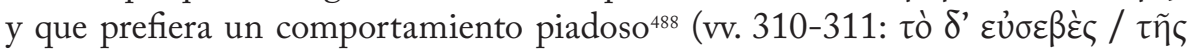

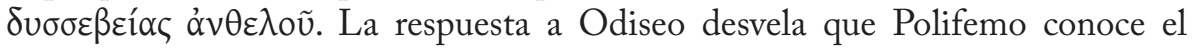
funcionamiento de las leyes helenas apropiadas para la llegada del extranjero, pues

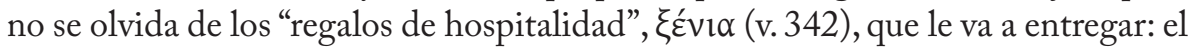
fuego, el agua y el caldero con que va a cocinarlo. Precisamente entonces Odiseo lamenta que el Cíclope sea óvóøıৎৎ (v. 348) e implora a Zeus Xenios. Por cierto

318-319. Cf. Ussher 1978: 100-101; Biehl 1986: 139; Napolitano 2003: 124.

${ }^{486}$ Cf. Calderón Dorda 2015a: 58; Vicente Sánchez, en prensa.

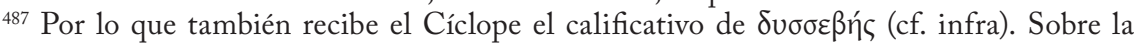

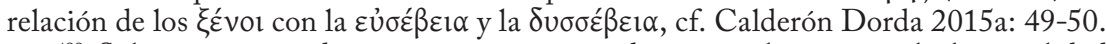

${ }^{488}$ Sobre este tipo de comportamiento piadoso en relación con la hospitalidad en la tragedia, cf. el comentario a E. Hec. 1232-1239. 
que la gravedad de la actuación del Cíclope incita a afirmar a Odiseo que, si Zeus no presta atención, en vano es considerado Zeus sin ser un dios para nada (v. 355:

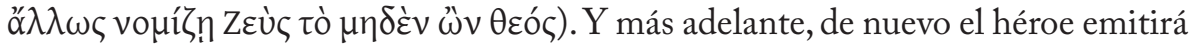
otra duda sobre los dioses, puesto que, si no recibe su ayuda divina para llevar a buen término su plan, habría que considerarlos inferiores al azar (vv. 606-607). Estas críticas de Odiseo hacia las divinidades se diluyen puesto que, finamente, consigue su objetivo, como veíamos que ocurría en las obras trágicas ${ }^{489}$.

Volviendo a la caracterización del Cíclope por parte de los personajes, continúa el Coro de Sátiros destacando sus transgresiones religiosas. En efecto,

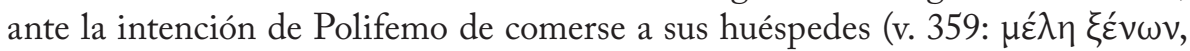

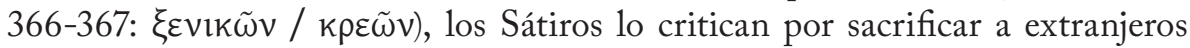

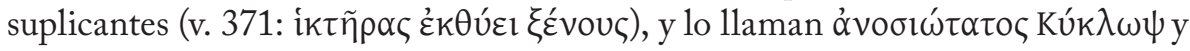
ávóolov kópa (vv. 378 y 438 respectivamente). Por lo tanto, de nuevo el adjetivo

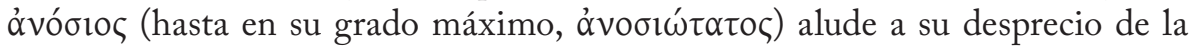
hospitalidad. Más adelante, Polifemo declara que se comerá el último a Odiseo, a lo que Sileno añade irónicamente que se trata de un hermoso privilegio

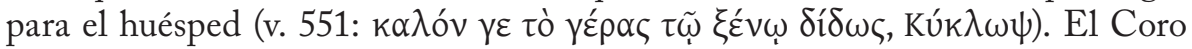
continúa refiriéndose al Cíclope en términos reveladores de su naturaleza

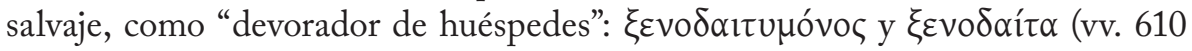
y 668). Finalmente, una vez se ha vengado Odiseo, le dice que es el castigo

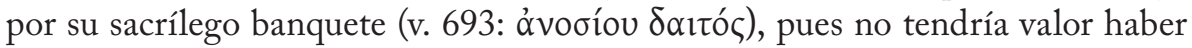
incendiado Troya si no hubiera podido castigar al Cíclope por el asesinato de

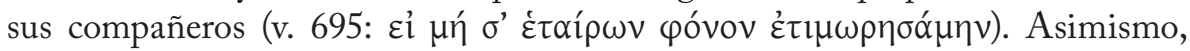
Polifemo recibe otras caracterizaciones a lo largo del drama que proceden de su actitud irreverente y profana, como el compuesto $\theta \varepsilon o \sigma \tau u \gamma \eta ́$, " detestado por los dioses" (vv. 396 y 602) ${ }^{490}$, ya que no se preocupa ni de dioses ni de mortales (v.

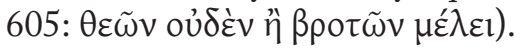

El pasaje seleccionado ilustra claramente ese rechazo hacia las divinidades: el dinero es dios, los promontorios marinos de su padre el dios Posidón nada le importan y, la más grave de sus transgresiones: considerarse más poderoso que Zeus. A través del análisis general realizado sobre este drama satírico, queda demostrado que la negación de las divinidades por parte de Polifemo y su ruptura de las relaciones de hospitalidad (que tanto ofenden a los dioses) provocan

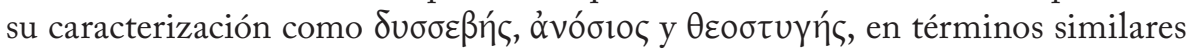
a los que presentan los textos trágicos para dichas situaciones.

${ }^{489}$ Estas expresiones estarían en sintonía con la negación de las divinidades citadas en el comentario a E. Hel. 1137-1150, empleando la primera (v. 355) un giro muy común para expresar la creencia o no en ellas con el verbo voú́\} $\omega$. Cf. el comentario a E. Ba. 1292-1305.

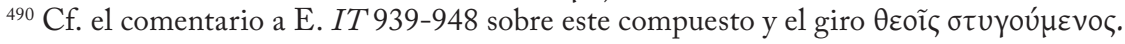

